This article was downloaded by: [University of Ballarat]

On: 22 July 2009

Access details: Access Details: [subscription number 907465156]

Publisher Routledge

Informa Ltd Registered in England and Wales Registered Number: 1072954 Registered office: Mortimer House, 37-41 Mortimer Street, London W1T 3JH, UK

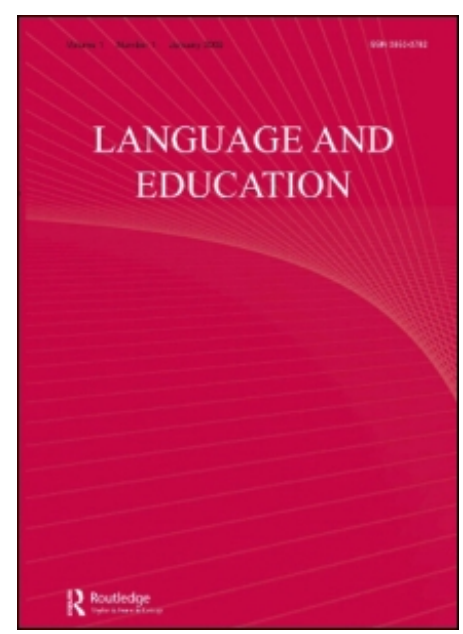

Language and Education

Publication details, including instructions for authors and subscription information:

http://www.informaworld.com/smpp/title content=t794297816

\title{
Pedagogy, School Culture and Teacher Learning: Towards More Durable and Resistant Approaches to Secondary School Literacy \\ John Smyth a
}

a School of Education, University of Ballarat, Australia

Online Publication Date: 15 September 2007

To cite this Article Smyth, John(2007)'Pedagogy, School Culture and Teacher Learning: Towards More Durable and Resistant Approaches to Secondary School Literacy',Language and Education,21:5,406 - 419

To link to this Article: DOI: $10.2167 / \mathrm{le} 802.0$

URL: http://dx.doi.org/10.2167/le802.0

PLEASE SCROLL DOWN FOR ARTICLE

\footnotetext{
Full terms and conditions of use: http://www.informaworld.com/terms-and-conditions-of-access.pdf

This article may be used for research, teaching and private study purposes. Any substantial or systematic reproduction, re-distribution, re-selling, loan or sub-licensing, systematic supply or distribution in any form to anyone is expressly forbidden.

The publisher does not give any warranty express or implied or make any representation that the contents will be complete or accurate or up to date. The accuracy of any instructions, formulae and drug doses should be independently verified with primary sources. The publisher shall not be liable for any loss, actions, claims, proceedings, demand or costs or damages whatsoever or howsoever caused arising directly or indirectly in connection with or arising out of the use of this material.
} 


\title{
Pedagogy, School Culture and Teacher Learning: Towards More Durable and Resistant Approaches to Secondary School Literacy
}

\author{
John Smyth \\ School of Education, University of Ballarat, Australia
}

\begin{abstract}
The relational, cultural and contextual view of literacy discussed in this paper has profound and widespread implications for the way teachers think about their students, their families, backgrounds and experiences and the aspirations students hold for the future. Focussing on the theoretical construct of teacher identity, the paper discusses the ways teachers worked and what happened to the culture of their schools when a structured literacy intervention enabled them to develop some agency as educational professionals, when provided with some 'social space' in respect of their literacy practices. The paper concludes that the teachers were involved to varying degrees in embracing changes that represented a move in the direction of a socially just pedagogy - the paper explains why.
\end{abstract}

doi: $10.2167 /$ le802.0

Keywords: school culture, sociocultural perspective, politics of teaching, socially just pedagogy, teacher identity, learner identity

\section{Introduction}

The starting point for this paper is an acknowledgement that what lies at the heart of the problem of advancing adolescent literacy in secondary schools is the intractable difficulty of redesigning the social institution of the high school in ways that make it a more relevant, amenable and hospitable learning environment for young people (see also May, this issue). The reason high schools are proving to be so obdurate to reform around the world is indicative of the depth and breadth of the complexities that have to be confronted (for a major elaboration see Smyth \& McInerney, 2007). As Moje et al. (2000: 165) put it, at the core of this is an understanding of the 'complexities of secondary literacy and learning', and the reality that young people today have a much greater role in the course of their lives in actively constructing their own literacies than any previous generation before them. Notions of literacy as somehow constituting linear transmission of neatly agreed upon bundles of content are no longer apposite today. We no longer have, if we ever did, 'tidy solutions to the complexities of classroom practice' (Moje et al., 2000: 165). Rather, what we have in respect of literacy in the secondary school context is something more akin to literacy events that need to be regarded as being 'situated in relationships with other 
people' (Moje et al., 2000: 165). In other words, what is involved in literacy can best be described as 'acts or moments that involve reading, writing, speaking, and performing many kinds of texts ... situated in specific social, cultural, historical and institutional contexts [which] are engaged in for specific purposes relative to those contexts' (Moje et al., 2000: 166).

In seeking to position this paper in terms of its broad orientation, its claims to knowledge and its theoretical perspective, I want to begin by addressing the longstanding claims in the literacy research literature, especially in respect of the United States, that there still remains a dearth of studies that present situationally located socioculturally informed approaches to literacy in secondary schools (see O'Brien et al., 1995: 446). O'Brien et al. lament that while some shift has occurred, it has still not had a major impact on the way literacy occurs in secondary schools. Ironically and somewhat perversely, this lag in sociocultural and situationally located school studies of literacy has now been overtaken in the United States by an official resurgent emphasis by the current Bush Administration on recognising only research that complies with so-called 'scientific research' criteria, which means, in effect, only studies that are randomised experimental field trials. Given the past history of the lemming-like way in which official educational policies have ricocheted around the world at the speed of sound, we can expect all other countries not already blighted to be similarly infected (cf. Whitehead, this issue). The methodological 'culture wars' are about to reach a new and unprecedented crescendo of vigour and intensity!

To stay with the United States for a moment, another aspect of the lament on the part of scholarly journals like the Reading Research Quarterly is that the delayed 'infusion' of new and different approaches and strategies to literacy into schools has been due, according to O'Brien et al. (1995), to the overwhelming preponderance of preservice and inservice courses as the vehicles for dissemination (see also Taylor et al., 2005). What this has meant, by implication, is that conservative and conserving views of literacy and how to research it, incubated in the academy, further serve to reproduce in largely uninterrupted ways the officially proclaimed view of what transpires in schools - notwithstanding that reality may be markedly different. The capacity of the academy to be informed as to more enlightened school-based alternatives is severely circumscribed, as is the capacity of schools to benefit from dialogue with the more progressive edges of thinking in universities.

The more relational, cultural and contextual view of literacy being pursued in this paper thus has profound and widespread implications for the way teachers think about their students, their families' backgrounds and experiences and the aspirations they hold for the future. Equally important is how teachers envisage and enact their teaching in ways that not only enable young people to value literacy, but that also allow them to see the part that literacy plays in helping them in their identity formation. Moje et al. (2000: 166) nicely captured this when they described literacy as a 'powerful tool that can be used to claim a space or establish an identity or voice in various social interactions. The ways one uses literacy can have a profound impact on whether a particular literacy event, and its concomitant practice, is valued'.

There are a number of equally important implications that flow directly from this view of literacy for the way we think and operate in secondary schools with 
regard to teachers' pedagogical identities, how they get to be shaped and the means by which they are supported and sustained. A central defining aspect here is the manner in which the culture of the school is able to interrupt the historical 'discourse of containment in pedagogical practice' (Popen, 2002) that has been the single most significant impediment to changing the high school. As long as literacy is limited in secondary schools to being 'somebody else's problem', then professional conversations will be diminished and of a deficit or blaming kind, and what gets lost as a consequence is the opportunity to learn from the teaching of others and to enrich a school's collective teaching repertoire for the benefit of students.

The remainder of this paper deals with the various elements of a 'professional development constellation' (Smyth, 2005) for literacy teachers and schools that emerged from the three-year Secondary Schools' Literacy Initiative (SSLI) funded by the New Zealand Ministry of Education. The notion of teacher professional development (PD) has emerged across all case study schools in the SSLI Research Evaluation as a prominent and emerging category, as schools move to embrace literacy across the curriculum. It was interesting to note the urgency with which schools took on the PD of their staff and of the different ways these were given expression depending upon local circumstances. How teachers experienced the need to change, how they had begun to rethink their teaching, how they picked up new ideas and tried them, how they modified some and incorporated others and, along the way, found new and enriching forms of support they had not realised existed within their schools, have all been exciting revelations of this study.

In brief it can be said that to varying degrees, teachers in this study engaged with PD at two interconnecting levels - first, at a process level, that had to do with practical matters of how to get new ideas, who had tried them before, with what effect, how to buy-in and who to access support from along the way; and, second, at a more strategic level, issues to do with their philosophy of teaching, how children learn, what kind of school culture is important to sustain teacher learning across the school and how their teaching might address issues of social justice and connect with the school's wider community and its agenda. These two levels are not unconnected (Smyth, 1987) nor are they linear; on the contrary, teachers seemed to move seamlessly between the two layers often in a to-and-fro way, honing process skills around literacy teaching while also taking on larger strategic issues (Smyth, 2001).

\section{The Construction of What It Means to Be a Literate Person}

There are two crucial intersecting categories associated with pursuing and developing and ultimately sustaining a literacy focus in ways that make a difference with students in secondary schools, and while it may make some conceptual sense to consider them as being separate, in reality they are interconnected, overlapping and highly interdependent. On the one hand, there is young people's project of developing a learning identity for themselves, and, on the other hand, there is teachers' development of an appropriate teaching identity in which teachers craft for themselves, with whatever support and resources they can obtain, an approach that engages students in learning. Intersecting with both of 
these is the wider social institutional agenda of the school identity, which is further mediated, modulated and moderated in various ways by the perceptions, values and aspirations held by society.

If I can speak more expansively for a moment, the notion of identity, or more accurately, 'identities', is a useful heuristic for thinking about what is happening when students make the decision to learn, and when teachers position themselves as engaging in the act of teaching. We also know that in the case of teachers, while identity formation is highly individualistic, how teachers acquire professional identities has important implications for the kind of PD they require. If the category of identit(ies) is to have any usefulness at all as an intellectual scaffolding for launching into discussion about teacher PD, then it will need a little elaboration.

As I have discussed elsewhere (Smyth, 2002, 2003, 2004), the term identity is in some danger of being overused and evacuated of meaning, but it still retains some usefulness as a way of referring to the 'experience of being a person' (Davies, 1994: 3). As an explanatory category, identity can be used to undermine the notion of an essential self - that is to say, the allegedly one true, stable, unchanging self, that can be discovered or that is considered as an 'already accomplished fact' (Hall, 1990: 222). Identity is 'not [therefore] something which already exists, transcending place, time, history and culture' (Hall, 1990: 225), but rather is a socially constructed 'production', which is never complete and always in process. Doing 'identity work' (Fraser et al., 1997; Snow \& Anderson, 1987) thus refers to 'the range of activities individuals engage in to create, present, and sustain personal identities that are congruent with and supportive of the self-concept' (Snow \& Anderson, 1987: 1348).

Whether we are using the term identity to refer to young people who are navigating pathways in making literate futures for themselves at school (or even outside of it), or their teachers who are trying to make sense of themselves as professionals - in both instances we are talking about individuals who are to varying degrees employing 'adaptive strategies . . . to accept, modify, or resist the institutional identities made available to them' (Fraser et al., 1997: 222). As Gecas (1982: 3) has argued, identity work, whether by children or adults, involves a complex process of negotiation in order to maintain 'one's overarching view or image of her or himself "as a physical, social, spiritual and moral being"' (cited in Snow \& Anderson, 1987: 1348), and the associated meaning individuals come to attribute to themselves, on the one hand, and, on the other hand, the social (or institutional) identities being made available to them by others.

Whitebrook (2001: 4) claims that identities are primarily 'a matter of the stories persons tell others about themselves, [together with] the stories others tell about those persons and/or other stories in which those persons are included'. Identity thus entails the integration of two aspects: 'what the self shows the world' or 'what of the self is shown to the world' together with 'what of the self is recognised by the world'. There is in this an element of inevitability around 'an absence of closure' (Whitebrook, 2001: 5) that brings with it 'instability', 'disorder', 'uncertainty', 'fragmentation' and even elements of the 'threatening' and the 'dangerous'. While there is surely an aspect of 'the individual, autonomous, rational chooser' (Whitebrook, 2001: 7) around the formation of identity, equally there is also 'in part, at least, of [this being done] in 
community' - in other words, identity is 'negotiated' and was something that became crucial in the SSLI schools as teachers reinvented themselves as 'literacy' teachers.

'Identity' is, therefore, a dynamic 'production' which is always in a process of becoming. What it means to be a literacy teacher needs to be read off against these ideas and seen somewhat in terms of developing an evolving vocabulary with which to talk about both the processes of the work of literacy teachers, and also the ways in which students come to regard themselves as literacy learners.

Using the notion of 'identity work' (Fraser et al., 1997; Snow \& Anderson, 1987; Wexler, 1992) as a conceptual category also enables us to capture something of the inevitable struggle that is occurring against the 'discrediting attributes' that come with the territory of attributed 'denigrating [or] stigmatised status' (Fraser et al., 1997: 222) - as is currently occurring with teachers, and some groups of students who are demonised by the media and some policymakers as being deficient in literacy skills. The literature on identity work makes it clear that not only are identities 'ongoing, tentative, changing, and dynamic', but they are 'assembled or constructed by selves and others', often in oppositional, contingent and shifting ways. Social, cultural, organisational and policy environments powerfully shape and strategically 'work on' actors in ways that amount to them revising their biographies according to circumstances, audiences and surroundings, but often in counter-hegemonic ways that push back into those conditions. As Snow and Anderson (1987) put it, identity work has various elements to it - 'distancing' or a kind of denial based upon difference from others; 'embracement' that amounts to acceptance and attachment and 'fictive story telling', involving exaggerations, embellishment and fantasising - each of which serves to enable teachers to manage the deformed images and 'spoiled identities' (Goffman, 1963) often reflected back to them by others.

Coldron and Smith (1999: 711) refer to the idea of 'active location in social space' as a way of explaining how teachers acquire the resources with which they fashion a teaching identity. They explain that social space 'is an array of possible relations that one person can have to others. Some of these relations are conferred by inherited social structures and categorisations and some are chosen or created by the individual ...', and how teachers' professional identities are formed depends largely on 'the quality and availability of these varied factors' (Coldron \& Smith, 1999: 711).

We might argue that the same can be said of learning identities of students, particularly in the ways they think about themselves in respect of literacies. Identities whether of teaching or learning are constructed through a process of 'active location in social space' (Coldron \& Smith, 1999: 711) 'active' in the sense that knowing what it means to be a teacher or a learner is relational, and is continually being modified in light of experience. That is to say, there are traditions or 'repositories of possible or actual practices and structures' (Coldron \& Smith, 1999: 713) that constitute fields of choices that either enhance or diminish the spaces within which teachers and students see themselves as having to make pedagogic/learning decisions. How they regard themselves in their work as teachers or learners has a lot to do with what kind of spaces they envisage themselves as having, and the kind of relationships they see as being possible. Coldron and Smith (1999: 711) note that 'policies that impose 
greater degrees of uniformity and conformity threaten to impoverish the notion of active location'.

In terms of what is happening to teachers' identities, Woods and Jeffrey (2002) point to the changed relationship that is embedded in the new 'technologies of regulation' (du Gay, 1997: 294) that are coming to increasingly govern the act of a teaching self and, by implication, a learning self. Trust, which is such a crucial element in the conduct of everyday life, is rapidly becoming depersonalised and 'invested in processes and abstract systems' (Woods \& Jeffrey, 2002: 90). Where once trust within teaching 'was localised and focussed through personal ties', moves toward an audit accountability mentality, as embodied in educational policies, results in 'less emphasis on the local factors through personal ties' (Woods \& Jeffrey, 2002: 95) and more emphasis on universal strategies and practices codified in written, standardised procedures. This 'diminution of trust' (Woods \& Jeffrey, 2002: 89) in teaching that invariably accompanies calls for and the imposition of more instrumental approaches, is having the effect of requiring teachers to relate to 'two or more competing discourses'.

Teachers who in the past might have seen themselves as having 'substantial' or more enduring identities, are rapidly needing to rework those identities in ways that reflect 'situational' or 'transient' identities that are more attentive to 'contextual location' (Woods \& Jeffrey, 2002: 90). The reason it is so important to understand something about teaching identity, and what is happening to it, is that how teachers regard themselves, how they are regarded by others, powerfully shapes how teachers relate to students. It is only when teachers feel valued, respected and trusted that 'children will feel they can take risks, and not be rejected as people' (Woods \& Jeffrey, 2002: 92).

There are a number of cogent conceptual reasons for foregrounding student and teacher identity in literacy around identity formation in the way in which I have done earlier, but one of the most significant has to do with the implications this has on how to frame teachers' learning in a PD context. In what follows, I want to focus for a moment upon some broad generative pedagogical approaches that link into professional learning of/for teachers, rather than specific classroom literacy strategies, which have been discussed by other contributors to this issue of the journal.

Reading off what teachers and students were telling us in the SSLI project, teachers in particular said they needed:

- Supportive and active spaces within which to learn about and act out, re-affirm or reframe their pedagogical approaches to literacy.

- Teaching contexts in which it is expected, and teachers are encouraged, to take risks and experiment with their teaching in the knowledge that risk-taking is a normal part of being a literacy teacher.

- Circumstances in which they can get to know their students as human beings, which might mean working collaboratively with colleagues in jointly planning and evaluating literacy learning experiences for students. It can also involve sharing knowledge with colleagues about students' lives and the impact this has on their learning.

- Develop collective understanding and pedagogical repertoires about what may 'make a difference' (Singh et al., 2001) in literacy practices, especially 
with students who present with the most complex lives and the most complicated learning difficulties in respect of literacy.

- Assistance in developing authentic forms of reporting student progress in literacy that are not simply about satisfying policy accountability requirements, but that are about bringing into existence genuine dialogical partnerships about student progress between students, teachers and parents (cf. Whitehead, this issue).

- Shared understandings about how to most effectively create the learning conditions for student voice in which students' lives, experiences and aspirations are brought into conversation with valued literacy knowledge of the school and in which students have a measure of ownership of their learning (see Smyth, 2006a, 2006b).

- Collegiality and forms of solidarity with which to confront and contest illinformed and ideologically-driven agendas on what constitutes literacy in schools.

- Leadership support in establishing and maintaining the legitimacy of a literacy focus across the school and the curriculum.

- Pursuing the creation of a culture in which teachers are not afraid of data but rather regard it as an important resource with which to track and diagnose student literacy progress so as to inform their teaching practices and the learning of their students.

If the conceptual starting point for this paper is the view that there is no longer such a thing as 'literacy' (singular), narrowly defined as reading and writing, but rather something much more complex that acknowledges the existence of 'multiple literacies', then this shift represents part of a much wider emerging view in which literacies are acknowledged as being 'an integral part of the sociocognitive and cultural lives of individuals and communities' (Bloome \& Paul, 2006: 293). This more expansive and inclusive view of literacy cannot but have profound implications as well for the way teachers are allowed to think about and enact their teaching. The avenues teachers regard as being available to students for 'acquiring academic knowledge', how the 'analysis, synthesis, [and] problem solving' occur and what constitutes 'innovative conceptualisation[s]' of what counts as knowledge (Bloome \& Paul, 2006: 293) are all part of this reconstituted view of literacies. What this reasoning says is that 'there are many routes to sophisticated ways of thinking' and that traditional conceptualisations of literacy that regard some students as being illiterate and failures because of family, home or cultural background, are no longer valid, if they ever were. The idea that there are a variety of ways of construing, acquiring, communicating and interrogating knowledge, 'as well as to create, analyse, and transform relationships among and between people and social institutions' (Bloome \& Paul, 2006: 294), has much to do with how teachers deal with the strengths that students bring with them to classrooms as learners.

A way of conceiving of what is occurring to teachers more generally, and this was exemplified in the New Zealand case of the SSLI research evaluation, is in terms of the struggle over the professional and pedagogical identity of teachers. According to Bernstein (1996), the tension is around what he labels the 'profane' (which constitute outer or extrinsic forces) and the 'sacred' (or intrinsic 
and inner forces) - and this struggle is a continuing hallmark of what it means to be a modern teacher. Stronach et al. (2002) speak in terms of teachers being involved in the daily struggle of working through 'professional identities [that are] in flux'. Both Bernstein and Stronach are alluding to the forces that would manage teachers more directly, that would more closely control what and how they teach and that would ensure that teachers are 'trained' and operate more efficiently without questioning, and that students likewise become similarly compliant. Official-preferred pedagogic identities of teachers endorse a managerialised view of knowledge that perpetrates a view of curriculum as being nothing more than a collection of 'singulars' (Bernstein, 1996). 'Good' teachers are, thus, portrayed as being receptive, acquiescent and compliant. While they might be easily manipulated, such teachers are evacuated of meaning, empty or hollowed out. The yearning is for knowledge that is certain, inert and easily able to be unproblematically transmitted to students who can be tested for their receptivity. If only the real world of teaching and learning were so simple! The real world of teaching, especially in high schools in which students come from diverse and complex backgrounds, is infinitely more complicated. Rather than teachers being scripted technical deliverers of narrowly prescribed curricula, they are, instead, constantly involved in making shifting professional judgments based upon the lives, experiences, hopes, aspirations and frustrations of their students.

Stronach et al. (2002: 109) make a useful distinction when they refer, on the one hand, to teachers' identities that reflect the notion of an 'economy of performance', broadly expressed in terms of the requirement upon teachers to conform to an 'audit culture', and, on the other hand, 'ecologies of practice' that are framed around teachers' individual and collective notions of professionalism. According to Stronach et al. (2002: 117) there is no such thing as a 'universal', 'self-sufficient', 'stable', 'definitive', 'stand alone' or 'core' notion of the teacher - to suggest that there is, 'is a false singularity'. What we have, instead, are 'fragmented', 'uncertain', 'non-unitary', 'shifting', 'contradictory' and 'unrealised' identities (Stronach et al., 2002: 116-117) that, to cite from Gluckman (1963), are more like 'cross-cutting identities' or 'oscillations' (Stronach et al., 2002: 117). Any attempt to present fixed typologies or professional stereotypes of teachers flies in the face of the realities of the inherent instability that comes with the work and does not properly account for the 'complex of occasional identifications [arising] in response to shifting contexts'. What we have, instead, is something more akin to 'shards of self-accounting' (Stronach et al., 2002: 116), as teachers move uneasily between imperatives that endorse notions as varied and contradictory as their need for autonomy, while engaging in criticism.

To stay with the category of ecologies of practice for a moment longer, Stronach et al. (2002: 121) say that 'ecologies can be "collectively experienced"' - a point I want to return to in a moment in relation to teachers in the SSLI. In a very real sense, the nature of teaching means that teachers are continually 'jockeying' or 'juggling' what they do to come to some uneasy settlements or allocations of priority around a 'plurality of roles' (Stronach et al., 2002: 118). They are constantly trying to resolve tensions from within the contexts in which they teach, such that: 
... professional selfhood [is] often a matter of addressing and 'resolving' these tensions and splits, whether in acts of accommodation, resistance, compliance, subversion - or, more commonly, a kind of bureaucratic cautiousness... (Stronach et al., 2002: 120)

What makes teaching so distinctive and different from many other forms of occupational work is that identities are profoundly shaped in the act of doing teaching: 'The most influential aspect of ecologies of practice seem. . to be the crucible of the classroom. It [is here] that innovations seem. . . to be. . . tested, adapted, resisted, embraced or ignored' (Stronach et al., 2002: 124; emphasis in original).

The argument I have been making so far is that teachers do not have singular, fixed identities, that they are complex creatures made even more so because of the continually shifting demands of their work and that the context and ecology of the classroom is a crucial defining factor in whether teachers take on new ideas or not. Added to this is the crucial part played by colleagues in helping to shape the collective ecology of practice.

Some of the 'generative themes' (Schoenbach \& Greenleaf, 2000) that emerged around teachers' ecologies of practice from schools in the SSLI that reflected the kind of complex identity formation just referred to, included:

(1) The opening up of spaces for professional conversations and dialogue about literacy;

(2) Teachers discovering that collectively they possessed strengths that they did not realise they had;

(3) Moving literacy beyond being portrayed in the school as 'somebody else's problem';

(4) Bringing teaching into the open in the sense that it is a public activity in which nobody in a school has a place to hide, and

(5) Shifting from a 'what works' mentality about literacy to a longer-term conversation around informed professional judgment. ${ }^{1}$

Teacher identity is important in whole-school approaches to literacy because as Haywood and Mac an Ghaill (1997) claim, in times of uncertainty and change, we must be interested in:

... offering new ways of critically understanding how state institutions help to produce and reproduce student cultural identities and social destinies, while at the same time exploring how these interact with young people's complex investments and contestations of state schooling.

One of the most significant ways that this was given expression in the SSLI was around the reconstrual of the notion of the secondary school. In many respects, the secondary schools that were making progress in sustaining schoolwide approaches to literacy in SSLI were the ones that had begun to confront and contest, with a modicum of success, the historically embedded and resilient notion of the culture of the high school (see also May, this issue). By this, I mean they had begun to contest the constellation of features that have historically framed and held in place the wider consciousness of what a high school is, in particular, as places characterised by: 
- Hierarchical forms of structuring - there is an institutionally legimitated hierarchy in which power is inequitably dispersed, with policymakers, administrators, subject experts and specialists at the top, with teachers in the middle who work within overall frameworks defined and set by others and, at the bottom, are students who have little or no say over their lives in school or how their learning is structured. As I have alluded to elsewhere, "this disparity of power is the "cause" of much alienation in secondary schools for many students' (Smyth et al., 2004: 59);

- High levels of subject specialisation - there is also the competitive academic 'curriculum hierarachies' (Connell, 1998; Teese, 1998: 401) that operate in secondary schools through the way particular subjects like mathematics and the physical sciences work to control what is constructed to be valuable knowledge in opening up access to universities and, hence, rewarding work and well-paid jobs. In other words, high schools reinforce another form of social stratification and exclusion, often around allegedly benign notions of choice, to further sustain inequalities, and

- A teacher-centred pedagogy - there is still a prevalence of didactic or transmission forms of knowledge that are predicated upon churning through large amounts of material to be regurgitated by students as markers of success in examinations. This acts to further entrench a view of learners as passive vessels, where there is a high level of acquiescence to right and wrong answers, and where learning is decontextualised and fragmented into sub-skills and routines - all of which militate against meaningful learning (Smyth et al., 2004: 57).

These features constitute what Elmore (1987) termed the 'continuity of practice' that acts to define secondary schools and that have to be struggled against in order for initiatives like the more robust notion of literacy being attempted in the SSLI schools to have a chance of succeeding. While not pervasive of all secondary schools, these features continue to represent a strong legacy that is not easily dislodged, and even trying to do so in ventures like SSLI was not without a considerable degree of personal and professional risk for the teachers involved.

The kind of continuities of practice literacy teachers need, and that were reflected in the kind of themes coming through the experiences of the SSLI schools, are ones that provide for:

- Schools that view themselves as active sites of 'knowledge production rather than knowledge transmission' (Wright et al., 2005: 20);

- An initial emphasis in literacy teaching that is upon teaching strategies that support literacy teaching that gradually shifts with experience and confidence to a focus on literacy learning by students;

- A process in which teachers progressively buy into a widening and deepening of what literacy means. For example, there is a staged process of Establishing, Consolidating and Sustaining (also see May, this issue) a commitment to literacy across the curriculum;

- Literacy opportunities for students in which they become active participants in their own learning;

- The feeling by literacy teachers that they are part of a wider school culture of innovation and experimentation; 
- Structured support for literacy teachers, for example, from the Regional Facilitator and school Literacy Leader (or coordinator) over time, to trial new literacy practices that are absorbed into their teaching;

- Access to resource people to guide teachers in making changes to their literacy teaching;

- Space in the course of the working day for teachers to talk openly with colleagues about literacy matters;

- Assistance to teachers in developing a shared vocabulary for talking with other teachers about literacy, often across conventional subject boundaries;

- Conversations between teachers in small work groups that enable them to feel safe in revealing things about their teaching of literacy;

- Opportunities for teachers to 'spread the word' about successful literacy practices that work for them;

- The belief that making changes to their teaching is worthwhile in the sense that their teaching is making a difference to students' literacy; for example, improved student attendance, improved teacher-student relationships, reinvigorated teaching colleagues, improved quality of professional dialogue, a climate supportive of risk-taking, a sharing among teachers in crosscurricular ways, and principles of literacy practice reflected in the policies, principles and practices of the department/faculty and the school.

- A view of literacy that is much wider than a technical set of teaching/learning skills, strategies and procedures, and that reaches into students' lives and aspects of the wider society. In other words, where there is a commitment to social justice centred on a belief by the school in the potential of all students to succeed academically, along with literacy programme that support this goal.

\section{Finale: Socially Just Pedagogy in Literacy Teaching}

A framework for tying together the previously appended list of bullet points (and I will highlight these in what follows with emphases) regarding the continuities of practice that emerged from the lives, experiences and practices of teachers and students in the SSLI, is to use the shorthand category of 'socially just pedagogy'. Drawing from Moje (2007), when teachers of literacy construct a teaching identity for themselves in which they enact and avail themselves of the kind of practices and opportunities alluded to earlier, then they are engaging in a socially just pedagogy. To put this another way, when teachers reinvent themselves and their teaching identities (often against the prevailing professional, policy and parental grain) in ways that reformulate what literacy means, then what they are doing is offering 'possibilities for transformation, not only of the learner but also of the social and political contexts in which learning and other social action take place' (Moje, 2007: 4). Most significant here is the way teachers are refashioning the institution of the high school, its established norms and persona in the wider public imagination and the longstanding tradition of how it is expected to operate. This is, indeed, courageous action! When teachers display a preparedness to participate in the kind of school and classroom activities exemplified in what was occurring in the SSLI, such as widening and deepening 
the meaning of literacy and making students active participants in their learning then, what we are witness to, in Moje et al. (2000: 408) terms, is a 're-inventing of adolescent literacy for new times'. In short, teachers are living and enacting a 'responsive literacy curriculum'. To act in this way in responding respectfully to adolescent lives is an open acknowledgment that students' 'literacy needs for new times are complex and demanding', and attending to them in these ways constitutes a 'professional model of practice'.

Elements of this professional model of practice, as Moje et al. (2000) refer to it, were evident in the ways teachers in SSLI schools assisted one another (as well as responded to forms of leadership) that exemplified a belief in the importance of creating a school culture of innovation and experimentation - in effect, a structured context of support for teachers in transforming themselves. In the SSLI, this was particularly evident in the provision of access to resource people in the form of in-school literacy coordinators and regional literacy facilitators to assist teachers as they went about developing a shared vocabulary for dialogue about their literacy teaching. A major part of this reculturing of teachers' work was an acknowledgement by the schools that they had to put the focus squarely on literacy learning by students, and that this was not possible without a tangible commitment by the school to provide the space within the course of a teaching day for teachers to engage in small work group conversations with one another in sharing their successes in literacy teaching. What followed inevitably from this is what Fullan (1982: 292), invoking Bruce Joyce, described as 'cracking the wall of privatism' in teaching. A not insubstantial part of this was the reconstrual of these schools in their own eyes and those of their communities, as active sites of knowledge production rather than mechanical and unthinking places of inert knowledge transmission. The 'remaking of teaching' (see Smyth \& Shacklock, 1998) underway, as literacy teachers created collegial forms of reflective practice about their literacy teaching, served to further bolster and reinforce teachers' beliefs that making changes to their teaching was worthwhile and that it was making a difference in terms of students' literacy. In a very real sense, once schools had embarked on this process of reinvention, then success contributed to further enhancing teachers' confidence as they spread the word about successful literacy practices that worked for them - among colleagues in their school, colleagues in other schools and with the wider community. In the end, the most potent element in this circuit breaker was the preparedness to move beyond paralysing deficit views of students' literacy and instead to regard students' lives, cultures and the communities as worthwhile places, in and of themselves, for literacy exploration. This commitment to a more expansive and less diminished view of literacy that involved reaching into students' lives and the wider society of which they were a part, was a powerful endorsement of the socially just and democratic belief that all students could succeed academically.

\section{Correspondence}

Any correspondence should be directed to Professor John Smyth, School of Education, University of Ballarat, PO Box 663, Ballarat, Victoria 3353, Australia (j.smyth@ballarat.edu.au). 


\section{Note}

1. Some of the more immediate issues of leadership, school organisation and roles and responsibilities of school principals, literacy leaders and regional literacy facilitators will not be dealt with here because they have been canvassed by May and Wright elsewhere in this issue.

\section{References}

Bernstein, B. (1996) Pedagogy Symbolic Control and Identity: Theory, Research, Critique (p. 23). Bristol, PA: Taylor \& Francis.

Bloome, D. and Paul, P. (2006) Introduction: 'Literacies of and for a diverse society'. Theory into Practice 45 (4), 293-295.

Coldron, J. and Smith, R. (1999) Active location in teachers' construction of their professional identities. Journal of Curriculum Studies 31 (6), 711-726.

Connell, R. (1998) Social change and curriculum futures. Change: Transformations in Education 1 (1), 84-90.

Davies, B. (1994) Poststructuralist Theory and Classroom Practice. Geelong, VIC: Deakin University Press.

du Gay, P. (ed.) (1997) Production of Culture / Cultures of Production. Milton Keynes: Sage/Open University Press.

Elmore, R. (1987) Reforming and the culture of authority in schools. Educational Administration Quarterly 23 (4), 60-78.

Fraser, J., Davis, P. and Singh, R. (1997) Identity work by alternative high school students. International Journal of Qualitative Studies in Education 10 (2), 221-235.

Fullan, M. (1982) The Meaning of Education Change. New York: Teachers College Press.

Gecas, V. (1982) The self concept. Annual Review of Sociology 8, 1-33.

Gluckman, M. (1963) Order and Rebellion in Tribal Africa: Collected Essays. London: Cohen \& West.

Goffman, I. (1963) Stigma: Notes on the Management of Spoiled Identity. New York: Simon \& Schuster.

Hall, S. (1990) Cultural identity and diaspora. In J. Rutherford (ed.) Identity: Community, Culture, Difference (pp. 222-237). London: Lawrence \& Wishart.

Haywood, C. and Mac an Ghaill, M. (1997) Materialism and deconstructivism: Education and the epistemology of identity. Cambridge Journal of Education 27 (2), 261-272.

Moje, E. (2007) Developing socially just subject-matter instruction: A review of literature on disciplinary literacy teaching. Review of Research in Education 31, 1-44.

Moje, E., Dillon, D. and O'Brien, D. (2000). Re-examining roles of learner, text, and context in secondary literacy. Journal of Educational Research 93 (3), 165-180.

Moje, E., Young, J., Readence, J. and Moore, D. (2000) Reinventing adolescent literacy for new times: A perennial and millenium issue. Journal of Adolescent and Adult Literacy 43 (5), 400-411.

O'Brien, D., Stewart, R. and Moje, E. (1995) Why content literacy is difficult to infuse into the secondary school: Complexities of curriculum, pedagogy and school culture. Reading Research Quarterly 30 (3), 442-463.

Popen, S. (2002) Democratic pedagogy and the discourse of containment. Anthropology and Education Quarterly 33 (3), 283-294.

Schoenbach, R. and Greenleaf, C. (2000) Tapping teachers' reading expertise: Generative professional development with middle and high school content-area teachers. Paper presented at the National Centre on Education and the Economy Secondary Reading Symposium, 2-5 March, Oakland, CA.

Singh, P., Dooley, K. and Freebody, P. (2001) Literacy pedagogies that may 'make a difference'. Asia-Pacific Journal of Teacher Education 29 (1), 49-71.

Smyth, J. (1987) Rationale for Teachers' Critical Pedagogy: A Handbook. Geelong, VIC: Deakin University Press.

Smyth, J. (2001) Critical Politics of Teachers' Work: An Australian Perspective. New York: Peter Lang. 
Smyth, J. (2002) Unmasking teachers' subjectivities in local school management. Journal of Education Policy 17 (4), 463-482.

Smyth, J. (2003) Undamaging 'damaged' teachers: An antidote to the 'self-managing school'. Delta: Policy and Practice in Education 55 (1 \& 2), 15-42.

Smyth, J. (2004) Policy research and 'damaged teachers': Towards an epistemologically respectful paradigm. Waikato Journal of Education 10, 263-281.

Smyth, J. (2005) When teachers experience engaging forms of professional development. Unpublished manuscript. Adelaide, Australia.

Smyth, J. (2006a) Educational leadership that fosters 'student voice'. International Journal of Leadership in Education 9 (4), 279-284.

Smyth, J. (2006b) 'When students have power': Student engagement, student voice, and the possibilities for school reform around 'dropping out' of school. International Journal of Leadership in Education 9 (4), 285-298.

Smyth, J., Hattam, R., Cannon, J., Edwards, J., Wilson, N. and Wurst, S. (2004) 'Dropping Out', Drifting Off, Being Excluded: Becoming Somebody Without School. New York: Peter Lang.

Smyth, J. and McInerney, P. (2007) Teachers in the Middle: Reclaiming the Wasteland of the Adolescent Years of Schooling. New York: Peter Lang.

Smyth, J. and Shacklock, G. (1998) Re-making Teaching:Ideology, Policy and Practice. London: Routledge.

Snow, D. and Anderson, L. (1987) Identity work among the homeless: The verbal construction and avowal of personal identities. American Journal of Sociology 92 (6), 13361371.

Stronach, I., Corbin, B., McNamara, O., Stark, S. and Warne, T. (2002) Towards an uncertain politics of professionalism: Teacher and nurse identities in flux. Journal of Education Policy 17 (1), 109-138.

Taylor, B., Pearson, D., Peterson, D. and Rodriguez, M. (2005) The CIERA school change framework: An evidence-based approach to professional development and school reading improvement. Reading Research Quarterly 40 (1), 40-69.

Teese, R. (1998) Curriculum hierarchy, private schooling, and the segmentation of Australian secondary education (1947-1985). British Journal of Sociology of Education 19 (3), 401-417.

Wexler, P. (1992) Becoming Somebody: Toward a Social Psychology of School. London: Falmer.

Whitebrook, M. (2001) Identity, Narrative and Politics. London: Routledge.

Woods, P. and Jeffrey, B. (2002) The reconstruction of primary teachers' identities. British Journal of Sociology of Education 23 (1), 89-106.

Wright, N., May, S., Whitehead, D., Smyth, J. and Smyth, S. (2005) Secondary Schools Literacy Initiative Research Evaluation. Sustaining Literacy Initiatives in Secondary Schools. Hamilton, NZ: Wilf Malcolm Institute for Educational Research, University of Waikato. 